\title{
ENSINO DA MATEMÁTICA: REFLEXÃO NAS TRAJETÓRIAS E TEMPOS DE ALUNOS
}

\section{TEACHING OF MATHEMATICS: REFLECTION ON PATHS AND TIMES OF STUDENTS}

Diego de Souza Oliveira (G-UEMS)

Jefferson Godoi (G-UEMS)

Fernando Luís Oliveira Athayde (UEMS)

Resumo: No presente artigo apresentamos resultados de pesquisa, focada no ensino de Matemática na Educação Básica e no Ensino Superior. Trata-se de estudo com ênfase nas dificuldades de ensino e aprendizagem que esta disciplina proporciona aos discentes no processo de formação escolar. Como aporte teórico, utilizamos as contribuições de Fiorentini (1995), Araújo e Luzio (2004), Freire (1996), Imbernón (2000), Prado (2000), Silva (1995), Piaget (1970) e outros, para pensar e refletir o ensino de matemática nas instituições de educação. A base empírica desse trabalho encontra-se alicerçada no contato e escuta dos alunos de duas escolas públicas de Paranaíba (MS) e do Curso de Matemática da Universidade Estadual de Mato Grosso do Sul (UEMS - Unidade de Cassilândia), tendo como objetivo a compreensão dos lugares que a matemática ocupa na educação escolar hoje. À medida que reflexões desse tipo vão sendo mais amplamente discutidas, tornam-se necessário detalhar e especificar seus limites e possibilidades na educação. Resultados iniciais indicam para a relevância do ensino de matemática nas unidades escolares e para a vida dos educandos, mas sinalizam, também, para inadequações no que se refere a conteúdos e metodologias em vigor no âmbito da educação escolar.

Palavras-chave: Matemática. Aprendizagem. Ensino.

Abstract: This paper presents results of research, focused on teaching of Mathematics in Basic Education and Higher Education. This is a study with emphasis on the difficulties of teaching and learning, this course provides students in the process of schooling. As a theoretical contribution, we use the contributions of Fiorentini (1995), Araujo and Luzio (2004), Freire (1996), Imbernon (2000), Prado (2000), Silva (1995), Piaget (1970) and others to think and reflect the teaching of mathematics in educational institutions. The empirical basis of this work is based on contact and listening to students from two public schools Paranaíba (MS) and the Course of Mathematics, State University of Mato Grosso do Sul (UEMS - Cassilândia Unit), aiming at understanding places that mathematics plays in school education today. As such reflections are more widely discussed, become necessary to detail and specify their limits and possibilities in education. Initial results indicate the relevance of mathematics teaching at schools and to students'lives, but signals also to inadequacies with regard to content and methodology in place as part of school education.

Keywords: Math. Learning. Education. 


\section{Introdução}

A ideia de que poucos conseguem apropriar-se do conhecimento matemático, ainda persiste nas instituições de educação, pois a complexidade da disciplina garante algumas exclusões. Alunos chegam à escola temendo a matemática, sentindo-se incapaz de compreendê-la. Legitima-se esta idéia pela representação da postura pedagógica de alguns professores matemáticos, se veem dono do conhecimento, mas sem escuta das necessidades individuais de seus alunos.

Atualmente, pode-se perceber que a educação passa por momento de reflexão acerca das possibilidades de um ensino mais significativo, na tentativa de superar velhos processos de ensino que não atendem às expectativas dos alunos e dos professores no processo ensino/aprendizagem. Nesta busca por novas maneiras de ensinar, emergem modismos nos processos metodológicos, mas entre formas antigas e novas de ensinar matemática, o professor pode ficar confuso. Porém, hoje parece ser consenso geral a necessidade de ensinar contextualizado, mesmo que para muitos, contextualizar é encontrar aplicações práticas para a Matemática a qualquer preço, mas isso não quer dizer que um conteúdo que não se consegue contextualizar, não serve para ser ministrado.

É difícil aceitar que, ainda assim, conhecedores desse percurso e de estudos de pesquisadores da educação, os quais afirmam que a criança constrói o conhecimento por meio da interação com o outro e com o mundo que o circunda, nossas instituições de educação insistam em manter um ambiente desmatematizador. Os programas escolares rejeitam ou não concedem reconhecimento aos saberes da criança e, mais concretamente, às formas culturais da infância e da juventude. (SANTOMÉ, 1998).

A aquisição do conhecimento ocorre quando o aluno estabelece significados entre as novas idéias e as suas já existentes e para que isso ocorra, o professor tem o papel de fazer o elo proporcionando a interação entre o conhecimento prévio do aluno e os novos saberes. A matemática oferece ao professor, diversas oportunidades de desafiar seus alunos a encontrarem soluções para as questões que eles enfrentam na vida diária. O processo de construção do conhecimento, como um ideário pedagógico, tanto coletivo como individual, é sempre dialético. (FIORENTINI, 1995).

O uso da história da matemática é fundamental para as práticas pedagógicas na sala de aula de matemática, pelo fato de o sentido dos fatos matemáticos estarem presentes na realidade dos alunos. Freire (1996) explica que educar é muito mais que realizar a prática da educação bancária que apenas treina o educando, mas é acima de tudo buscar novas metodologias de ensino para que a sala de aula de matemática torne-se um local de investigação, produção de conhecimentos e de experiências.

A Matemática ${ }^{1}$ tem história e surgiu justamente na interação do homem com seu mundo, ao tentar espontaneamente compreendê-lo e atuar nele. $O$ número surgiu da necessidade que as pessoas tinham em contar objetos e coisas. Nos primeiros tempos da humanidade para contar eram usados os dedos, pedras, nós em corda, marcas em ossos, etc.

\footnotetext{
${ }^{1}$ D’Ambrosio (2002), denominou de Matemática Espontânea os métodos matemáticos desenvolvidos por povos na sua luta de sobrevivência.
} 
Na verdade, a história dos números é apenas uma parte da historia da humanidade. Investigar a sua origem é investigar a pré-história humana.

A etmologia da palavra matemática é de origem grega: máthēma $(\mu \alpha ́ \theta \eta \mu \alpha)$, significa ciência do conhecimento e da aprendizagem e mathēmatikós ( $\mu \alpha \theta \eta \mu \alpha \tau \iota \kappa o ́ \varsigma)$ é o apreciador do conhecimento que busca a ciência do raciocínio lógico e abstrato, que envolve uma permanente procura da verdade, por meio do rigor e precisão. Para pensar a origem desta ciência, verificamos que os textos matemáticos mais antigos são do Egito antigo (1850 aC $600 \mathrm{aC}$ ), Mesopotâmia (cerca de 1800 a.C.) e Índia antiga (800 a.C. - 500 aC), referem-se ao chamado Teorema de Pitágoras.

Entretanto, há registros matemáticos na Pré-História que indicam medição de um processo rudimentar de contagem, utilizando marcas em galhos, ranhuras em ossos, desenhos em cavernas (pintura rupestre) e pedras. Pesquisadores afirmam que nesta mesma época surgem as primeiras tentativas para quantificar, ou seja, para cada unidade obtida, era colocada uma pedra em cada saquinho. (BOYER, 1996).

Quanto à numeração escrita, é preciso dizer que nasceu do desejo dos povos primitivos de manter registros de bovinos ou outros bens (objetos), com marcas ou traços em paus, pedras e outros. Os sistemas de registros numéricos, mais antigos que se conhecem são os da civilização egípcia e dos babilônios que, segundo os antropólogos, datam aproximadamente do ano 3.500 a.C.. A ciência e a matemática na Mesopotâmia e no Egito tinham caráter prático e com intensa presença participativa dos sacerdotes que detinham o conhecimento, na época.

As matemáticas orientais surgiram como uma ciência e com característica prática, tendo como ponto central de utilização a facilidade para o cálculo do calendário, a administração das lavouras e colheitas, organização de obras públicas e a cobrança de impostos e seus registros. (BOYER, 1996).

A Matemática ao contrário do que poderíamos supor, não esteve, em seu início, entre os gregos. É preciso ressaltar que essa mudança seria iniciada apenas por volta do século VI a.C.. Pois a construção da educação grega, nesse longo período inicial, representou um retrocesso em relação à antiga educação dos escribas egípcios e babilônios, uma vez que ela, ao contrário das outras civilizações, não daria importância à cultura letrada.

No século VI a.C., encontramos na a educação grega, especialmente em Atenas, a valoração pelo ensino da leitura e da escrita para a formação dos filhos dos nobres. Todavia, tivemos que esperar, pelo menos mais um século, para ver o ensino de Matemática começar a ser considerado essencial para essa formação do jovem grego. Neste mesmo século (VI a.C.), em colônias gregas no litoral da Ásia Menor, fazem-nos assistir ao nascimento da matemática moderna, como principal estimulador Tales de Mileto (considerado o pai da matemática moderna), entretanto, foi Pitágoras de Samos (c. 580-500 a.C.) um filósofo da mesma época de Tales, que exerceu influência maior, e definitiva, não apenas na Matemática, mas também no seu ensino. (MARROU, 1975).

Assim, na tentativa de encontrar respostas racionais para as questões sobre a origem e a essência do mundo, os pensadores jônicos descobriram na matemática uma fonte muito rica de conhecimento. Entretanto, não seria aquela Matemática com essência prática que eles conheceram em sua viagem ao Egito e à Babilônia, mas sim, uma nova matemática, que 


\title{
INTERFACES DA EDUCAÇÃO
}

ajudaria a "encontraria a ordem no caos, a ordenar as idéias em seqüências lógicas, a encontrar princípios fundamentais, ou seja, uma matemática racional. (STRUIK, 1992).

\section{Desafios do Ensino da Matemática}

Recentes pesquisas evidenciam baixo aproveitamento nos cursos de ciências exatas, principalmente, na matemática, pois são graduações que mais se destacam quando se trata de desistências apesar de sobrar poucos alunos, estes foram algumas vezes reprovados ${ }^{2}$. Sabemos que na vida, ninguém gosta enfrentar dificuldades, suportar dores ou ter sofrimentos indevidos, por outro lado, as coisas que são capazes de provocar satisfação real nas pessoas não causam aborrecimento a elas, porque nelas, os sujeitos sempre descobrem experiências novas. É razoável pensar nas abordagens de conteúdos matemáticos que não conseguem dar satisfação aos alunos ou manter seu interesse, estão desvinculados de sua realidade.

\begin{abstract}
Em muitas ocasiões os conteúdos são contemplados pelo alunado como fórmulas vazias, sem sequer a compreensão de seu sentido. Ao mesmo tempo, se criou uma tradição na qual os conteúdos apresentados pelos livros didáticos aparecem como os únicos possíveis, os únicos pensáveis. (SANTOMÉ, 1995, p. 161).
\end{abstract}

Os estudos de Vygotsky, Bruner e Ausbel indicam que ser mediador entre o objeto e o sujeito do conhecimento pede do educador postura e desenvolvimento de algumas atitudes. Dentre essas atitudes, a de descobrir o que o aluno já conhece e criar condições para que o aluno possa passar do particular para o geral e deste para aquele, de tal maneira que ele mesmo seja capaz de construir seu conhecimento com significado. Pensamos ser este um dos aspectos mais nobres do processo de aprendizagem escolar, pois nesta passagem, o particular tem que se relacionar com a realidade vivida pelo aluno. (MOYSÉS, 1994).

As salas de aula apresentam contextos complexos e fervilhantes servindo, desta forma, propósitos e grande variedade de processos e acontecimentos. Os professores devem gerir grupos, lidar com necessidades individuais específicas, promover a aprendizagem, estabelecer rotinas e outros. A melhora do ensino da matemática nas escolas públicas e privadas depende, principalmente, da melhor capacitação de professores. É crucial que eles estejam bem preparados, e isso significa dominar o conteúdo daquilo que deve ser ensinado e conhecer as melhores estratégias para o ensino. (ARAÚJO, 2004).

Os docentes da educação básica têm variedade de coisas para fazer, na escola, e faz mais de uma coisa ao mesmo tempo. É esse obstáculo na vida profissional do professor, que o faz viver em constante reflexão acerca da grande problemática do ensino/aprendizagem e sua própria formação. É importante acrescentar a união entre teoria e prática, pois elas são formas de superar a mediocridade na educação escolar.

Queremos insistir que, embora nos restringindo à figura do professor, não nos escapa que o problema da competência pedagógica tem sua raiz na questão política

\footnotetext{
${ }^{2}$ Observação da vivência acadêmica dos discentes da pesquisa.
} 
da educação. Não temos dúvida de que a grave crise só por que passa a escola pública brasileira é fruto do descaso com que os governantes a vêm encarando. Se o discurso oficial pode-se captar uma certa intenção manifesta de melhorar o ensino básico - a maioria dos governantes tem insistido nesse ponto nos últimos anos - a realidade, no entanto, nos mostra quão vazio é esse discurso. E, em função dessa política de aviltamento do magistério, a escola passou a ter, em seus quadros, profissionais malpreparados, desmotivados e, o que é pior, descompromissados com o seu papel de agentes de mudança. (MOYSÉS, 1994. p. 15-16).

A escola pública que deveria solidificar transformações na sociedade a faz de forma duvidosa, pois tantas são as rejeições e descasos com a qualidade do ensino público que perdeu o prestígio. Infelizmente o ensino da matemática, tradicionalmente, ainda se faz sem fazer referência ao que o aluno já sabe ou precisa saber. Apesar de todos reconhecerem que o aluno pode aprender fora da aula, o tratamos como se nada soubesse, sobre tópicos ainda não ensinados. As críticas acerca dos resultados negativos do ensino da matemática levam professores comprometidos com a educação da matemática nas séries iniciais do ensino fundamental e na graduação a buscarem caminhos para solucionar essas deficiências apresentadas pelos alunos, estão buscando ensinar a matemática voltada à realidade dos alunos.

O professor deve ajudar a desenvolver um conhecimento profissional que the permita avaliar a necessidade potencial e a qualidade da inovação educativa que deve ser introduzida constantemente nas escolas: desenvolver habilidades básicas no âmbito de estratégias de ensino em um determinado contexto e proporcionar as competências para ser capaz de modificar as tarefas educativas continuamente, numa tentativa de adaptação à diversidade e ao contexto dos alunos; comprometer-se com o meio social. (IMBERNÓN, 2000).

\section{A Matemática no Ensino Fundamental}

Ensinar Matemática sem explicitar a origem e as finalidades dos conceitos é contribuir para o insucesso escolar da disciplina. Todavia, um dos objetivos fundamentais da educação é criar no aluno competências, hábitos e automatismos úteis, bem como desenvolver capacidades reflexivas. Contudo, no âmbito das instituições escolares, a matemática não é vista como uma linguagem capaz de traduzir a realidade e estabelecer suas diferenças.

Conhecimento matemático se manifesta como uma estratégia para a realização das intermediações criadas pelo homem, entre sociedade e natureza. Entretanto, a construção desse conhecimento pelos alunos ainda está muito longe de ser alcançado, pois a prática pedagógica desenvolvida na educação ainda é carregada de metodologia tradicional, que em alguns casos não permitem aos alunos construírem aprendizagem. Na escola a criança deveria envolver-se com atividades matemáticas que educam e construam aprendizagem significativa.

Os alunos afirmaram na entrevista que a matemática do ensino fundamental é apresentada muito objetivamente e sem utilidade. Quando perguntamos para alguns alunos, o que pensam do ensino desta disciplina, respondem de forma negativa, caracterizando-a como um contratempo para que encontrem dificuldades no conteúdo e para reprová-los.

Porém, se é feita uma pergunta em sala de aula que se relaciona a uma conta matemática, principalmente no que diz respeito a cálculos das quatro operações, todos 


\section{INTERFACES DA EDUCAÇÃO}

disputam para dar a resposta correta primeiro, segundo eles, quem sabe matemática é bom aluno.

A matemática da escola é racional, é ordenada, é lógica. Esta é a sua identidade. Se esta é a identidade, é a positividade matemática, é a sua universalidade, outras manifestações são avaliadas como negativas; ou seja, todos aqueles que pensam com a emoção, com os sentimentos, que tentam outras formas de saber, que buscam compor uma outra lógica. Esses são marcados por uma identidade, pois que esses não são bons, é aí onde a força homogeneizadora vai atuar. (SILVA, 1995).

Para muitos que dizem não gostar do conteúdo matemático, deixa a impressão que o professor desta disciplina é ditador em sala de aula, torna a aula tradicional e sem rendimento, provoca cansaço nos alunos e pouca participação nas aulas. Infelizmente o ensino da matemática, em muitas escolas e por muitos professores, continua direcionado para atuar como um instrumento disciplinador e excludente. Uma boa parte dos docentes tem como único objetivo ensinar a matemática sem se preocuparem em repassar para o aluno um conhecimento matemático mais significativo.

A escola que está posta, apresenta pouca participação da comunidade, fragmentada na forma de pensar a educação, relaciona a disciplina do aluno, estar quieto e cumprindo as ordens estabelecidas pelo professor, as salas de aula com carteiras em fileiras, professor colocado à frente, apenas com uso de quadro, giz e livro didático, dando instruções para os alunos. Percebemos que o professor acredita na transmissão de conhecimentos como única forma de aprendizagem, desconsidera a comunicação como uma interação entre sujeitos.

Por outro lado, temos bons profissionais que estão preocupados em desmistificar o ensino da Matemática e acreditam que é possível alcançar esses objetivos desde que seja levado em consideração a realidade e as influências sofridas pelos alunos no seu meio e na sala de aula. Porém, às vezes a escola trabalha de forma muito mecânica, usando regras e fórmulas. Essa matemática da memorização não é a ideal, é automatizadora e a escola usa mais esse tipo de ensino que é o oposto do que deveria ser a matemática. Para o aluno se desenvolver sem ficar memorizando regras e fórmulas é necessária uma boa metodologia. Lima (2001) afirma que não se aprende passivamente matemática, os exercícios e a contextualização ajudam a usar conceitos e proposições, desfazem certos mal-entendidos, ajudam a fixar na mente idéias novas, dão oportunidades para explorar as fronteiras da validez das teorias expostas no texto e reconhecer a necessidade das hipóteses.

Entretanto, percebe-se que a afirmação acima parece não ser usada com tanto êxito no ensino da disciplina discutida, pois a maioria dos professores da área nem querem saber se aluno está aprendendo ou não, e, em muitos casos, querem apenas passar o conteúdo.

A reflexão sobre os dados obtidos na pesquisa possibilitou a construção de um gráfico. Veja qual a relação da disciplina de Matemática como os alunos do Ensino Fundamental: 


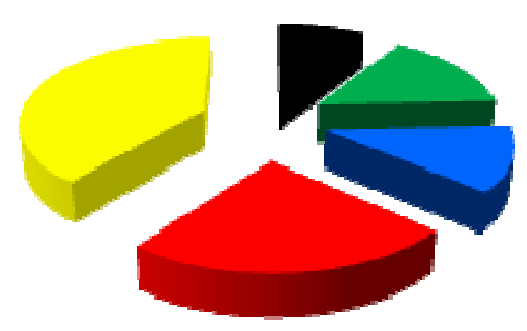

- Gosta da Matemática;

- Tem interesse pela disciplina;

- Tem um pouco de interesse pelos

conteúdos de Matemática;

- Tira média para não reprovar;

Não gosta da Matemática;

Assim, por meio de entrevistas no pátio da escola e com as análises dos dados obtidos, aproximamos da construção de estratégias que busque conciliar interesses e necessidades que desperta motivação e favorece o sucesso do processo ensino-aprendizagem na matemática. Segundo D'Ambrosio (2002), é importante abrir espaço para que o conhecimento do aluno se manifeste. Como uma vez disse Guimarães Rosa ${ }^{3}$ : Mestre é aquele que às vezes pára para aprender. Daí a grande importância de se conhecer o aluno, exigindo do professor uma característica de pesquisador.

\section{A Matemática no Ensino Médio}

No Ensino Médio, o comportamento dos alunos não é muito diferente do Ensino Fundamental, porém todos eles assumem outra postura em sala de aula, o que os torna mais interessados e responsáveis em todas as disciplinas. Mostram maior empenho nas disciplinas de matemática e química, mesmo sendo aquelas que mais apresentam dificuldades. Entretanto, isso só acontece, porque eles querem alcançar um único objetivo, o curso superior. É necessário o aprendizado das exatas (a matemática), mesmo que não gostem.

Para nós foi fácil ver o interesse dos alunos de Ensino Médio. Perguntamos a eles o que tinham a dizer sobre ensino da matemática, e expressam que é complicado, mas é essencial para o futuro, pois querem cursar uma faculdade. No entanto, na entrevista individual individualmente (25) alunos, obtivemos os seguintes resultados:

3 João Guimarães Rosa, mais conhecido como Guimarães Rosa (Cordisburgo, 27 de junho de 1908 - Rio de Janeiro, 19 de novembro de 1967), foi um dos mais importantes escritores brasileiros de todos os tempos. Foi também médico e diplomata. Os contos e romances escritos por João Guimarães Rosa ambientam-se quase todos no chamado sertão brasileiro. A sua obra destaca-se, sobretudo, pelas inovações de linguagem, sendo marcada pela influência de falares populares e regionais.

\begin{tabular}{|l|l|l|l|l|c|}
\hline Interfaces da Educ. & Paranaíba & v. 1 & n. 3 & p.23-33 & 2010 \\
\hline
\end{tabular}




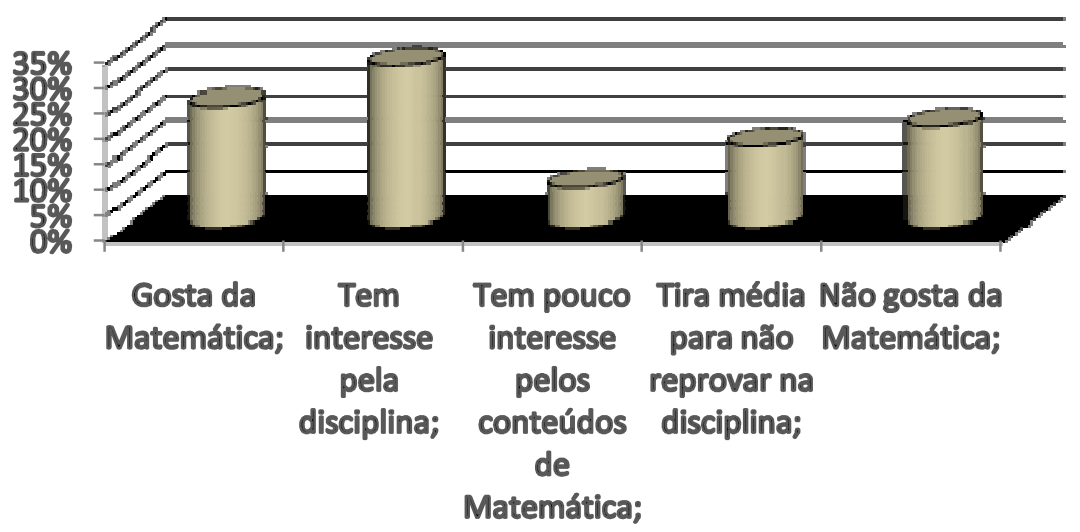

Observamos nos dados obtidos que os alunos não aceitam a matemática como as outras disciplinas (Geografia, História, Língua Portuguesa, Artes e outras), mostraram consciência responsável nos estudos da matemática, mas para o vestibular. Falaram sobre seus professores e fizeram comparações incríveis entre os docentes de outras disciplinas (exatas e humanas), levando-nos a acreditar que os professores/matemáticos são interpretados por eles, como carrascos, e em alguns casos, nem saibem o que estão falando, mesmo assim, afirmaram que para serem aprovados, cumprem as regras impostas por medo de serem reprovados na disciplina (exatas).

\section{A Matemática no Vestibular}

Entra os cálculos mais uma vez para assombrar a todos, para causar maior aflição na hora da realização da prova de vestibular, lembrando que independente da área de escolha para a graduação, todos tem na matemática um teste de conhecimento para a aprovação no curso escolhido, terão que ser aprovado nesta disciplina!

Para muitos, a matemática torna-se um obstáculo quando é necessário realizar uma prova de vestibular, pelo fato de ser exata. Isso leva a maioria dos candidatos a assinalarem uma única alternativa em todas as questões de matemática, pois somente assim terão realmente certeza que acertarão pelo menos uma questão, o que irá influenciar na sua nota não deixando-o zerar na avaliação, o que significa reprovação.

Alunos vestibulandos afirmaram que não estudam o conteúdo programatório para o vestibular. Dedicam-se apenas na memorarização da tabuada, pelo menos isso serve para ter uma base e responder na prova. Sabemos que isso é um erro, pois o conteúdo programático é tão restrito e amplo, que se torna um grande desafio estudá-lo no dia da prova e realizá-la bem.

Atualmente, percebe-se o quanto houve queda no percentual de concorrentes para os cursos de ciências exatas e aumento na concorrência para os cursos das ciências humanas e biológicas, tudo isso decorrente do alto índice de dificuldades apresentados nas provas de vestibulares, mas os candidatos das áreas humanas e biológicas quando expõem os seus pontos de vista, dizem que não tem necessidade de colocar alternativas de matemática nas 
suas provas, pois eles não irão usar certas coisas que ali está para ser resolvido, dessa maneira, talvez, preferem optar por um curso técnico, onde não existe a necessidade de prova para aprová-los ou reprová-los.

Tudo indica que os alunos dependem da matemática. Na pesquisa que realizada notamos que alunos de Ensino Médio sofrem uma grande mudança quando vão para o vestibular. Entretanto, quando fizemos a pergunta: qual a importância da matemática em sua vida? Responderam:

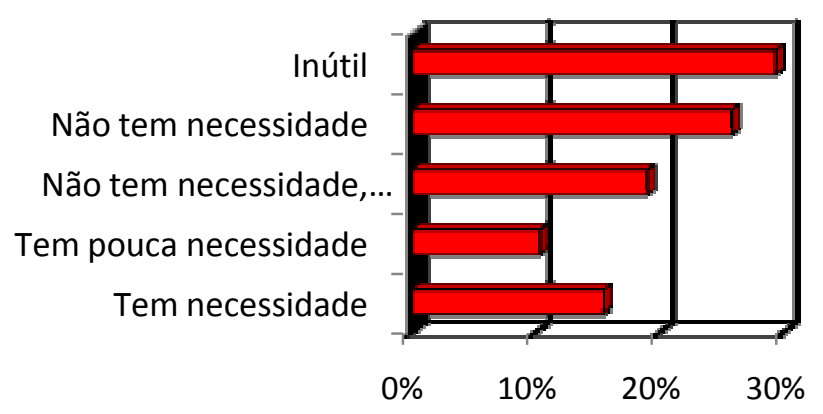

Fonte: Dados de coleta de campo realizada com alunos de cursinho pré-vestibular público de Paranaíba.

Os resultados indicaram que boa parte dos alunos estudam a matemática para alcançar o curso superior e, depois disso, não vêem necessidade do conteúdo para a sua vida.

\section{A Matemática no Ensino Superior}

A matemática no Ensino Superior assume uma posição não mais relevante, se analisarmos as opiniões dadas pelos alunos da Educação Básica, pode ser que tenhamos certeza que o curso passa por transição, por falta de alunos.

O curso de matemática se divide em dois tipos, o de licenciatura e o de bacharelado. $\mathrm{O}$ curso de licenciatura em matemática abrange especialmente a área de educação, ou seja, é a parte da matemática que dispõe ao aprendizado, a possibilidade de lecionar a disciplina. $\mathrm{O}$ curso de bacharelado em matemática traz consigo uma didática um pouco diferente, onde o curso prepara os alunos para serem profissionais exclusivos da matemática pura.

A pesquisadora Suely Druck ${ }^{4}$, afirma que a enorme procura por professores de matemática estimulou a proliferação de licenciaturas. Nas faculdades, há muita vaga e pouca qualidade, o que transforma as licenciaturas em cursos atraentes para os que desejam um diploma qualquer. Produz-se, assim, um grande contingente de docentes mal formados ou

\footnotetext{
${ }^{4}$ Doutora em matemática pela Pontifícia Universidade Católica do Rio de Janeiro, com pós-doutorado pela Université de Paris, Suely Druck é professora da Universidade Federal Fluminense (UFF). Disponível em: $<$ http://portaldoprofessor.mec.gov.br/conteudoJornal.html?idConteudo=745>. Acesso em: 25 maio 2010.
}

\begin{tabular}{|l|l|l|l|l|c|}
\hline Interfaces da Educ. & Paranaíba & v. 1 & n. 3 & p.23-33 & 2010 \\
\hline
\end{tabular}


desmotivados. Esse grupo, em alguns casos, atua também no ensino superior, sobretudo nas licenciaturas, criando um perverso círculo vicioso.

A Matemática não é uma ciência cristalizada, imóvel, fechada, monolítica, abstrata ou desligada da realidade. Ao longo dos tempos, como mencionamos no início do texto, esteve ligada a diferentes áreas do conhecimento, respondendo a muitas questões e a necessidades do homem, ajudando-o a intervir no mundo que o rodeava.

Segundo os resultados da pesquisa realizada no ano de 2009, na Universidade Estadual de Mato Grosso do Sul (UEMS-UUC), elaboramos um gráfico para contextualizar a situação da permanência dos discentes no Curso de Matemática na Unidade Universitária de Cassilândia. Vejamos:
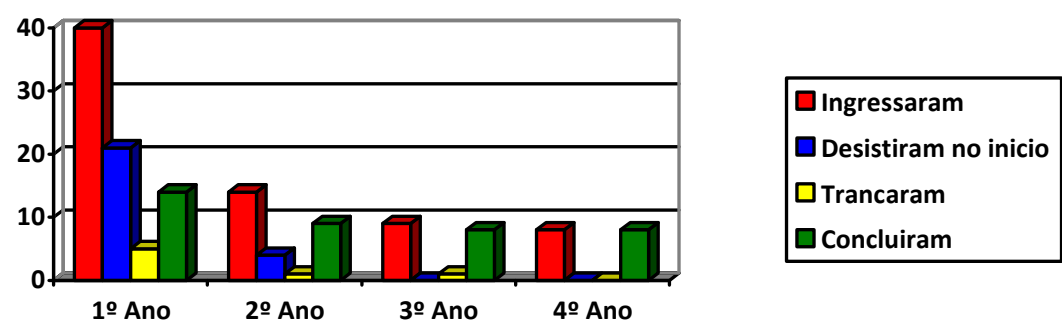

Não podemos abordar os problemas do ensino da matemática na graduação somente do ponto de vista metodológico e curricular, pois isso seria um erro grave. Entretanto, a pesquisa aponta para um alto índice de desistência. Sendo assim, torna necessário rever os objetivos dos Cursos de Matemática, tais como: grade curricular, propostas metodológicas, procurar entender as motivações dos que procuram a licenciatura em matemática, condições de trabalho com que se deparam, dificuldades de permanência no curso e outros.

\section{Considerações Finais}

A pesquisa aponta para mudança na metodologia e no currículo em rigor, pois matemática é parte ativa na vida de todos, mesmo com suas complexidades e complicações ela é muito necessária para todas as fases da vida humana e nenhum estudioso da questão ousa afirmar o contrário.

A construção do conhecimento nas Instituições de Educação Básica exigem novas metodologias e ambientes desafiador, pois cada nova turma de alunos é formada por um grupo heterogêneo. Não valorizar esta especificidade, o curso não atenderá às dificuldades e necessidades que os alunos sentem e pedem. É importante uma educação mais ampla, pois aprender a aprender faz parte do cotidiano dos alunos e dos professores.

Acreditamos que as Instituições de Educação Superior deveriam ser alicerçadas no diálogo e na escuta dos alunos em formação. Um ambiente matematizador é permeado por desafios, por construções e possibilidades de saberes. O professor envolvido neste processo deve ser aquele que possibilita esse ambiente, que leva o aluno a estabelecer relações do 
pensar, indo além do que vê. Sendo assim, virá a descobrir o conhecimento, construído de forma ativa, posicionado como parte fundamental desse mundo, capaz de promover mudanças em si mesmo e em seu meio, e ver na Matemática um produto cultural capaz de produzir resultados específicos da sua realidade.

\section{Referências}

ARAÚJO, C. H.; LUZIO, N. Dificuldades do ensino de matemática. INEP, 2004. Disponível em: <http://www.inep.gov.br/imprensa/artigos/>. Acesso em: 12 jan. 2005.

BOYER, C. B. História da Matemática. São Paulo: Edgard Blücher, 1996.

D’AMBROSIO, Ubiratan. Etnomatemática: elo entre as tradições e a modernidade. Belo Horizonte: Ed. Autêntica, 2002.

FIORENTINI, D. Alguns modos de ver e conceber o ensino da Matemática no Brasil. Revista Zetetikê. Ano 3, n.4, Campinas/SP: UNICAMP, 1995, pp. 1-35.

FREIRE, P. Pedagogia da autonomia: saberes necessários à prática educativa. São Paulo: Paz e Terra, 1996. Campinas: UNICAMP/FE/CEMPEM, 1995. p. 1-37.

IMBERNÓN, F. Formação docente e profissional: formar-se para a mudança e incerteza. São Paulo: Cortez, 2000.

LIMA, E. L. Matemática e o Ensino. Rio de Janeiro: Ed. Sociedade Brasileira de Matemática, 2001 .

MARROU, H. I. História da educação na antiguidade. São Paulo: EPU, 1975.

MOYSÉS, L. O desafio de saber ensinar. Campinas: Papirus, 1994.

SANTOMÉ, J. T. Globalização e Interdisciplinaridade: o currículo integrado. Porto Alegre: Artes Médicas, 1998.

SILVA, T. T. da. Alienígenas na sala de aula: uma introdução aos estudos culturais em educação. Petrópolis: Vozes, 1995.

STRUIK, D. J. História Concisa das Matemáticas. Lisboa: Gradiva, 1992. 